\title{
Potential Antiarrhythmic Effect of Methyl 3,4,5-Trimethoxycinnamate, a Bioactive Substance from Roots of Polygalae Radix: Suppression of Triggered Activities in Rabbit Myocytes
}

\author{
Zhenghang Zhao, ${ }^{* a, b}$ Minfeng Fang, ${ }^{c}$ Dandan Xiao, ${ }^{a}$ Mei Liu, ${ }^{a}$ Nadezhda Fefelova, ${ }^{b}$ \\ Chen Huang, ${ }^{a}$ Wei-Jin Zang, ${ }^{a}$ and Lai-Hua $\mathrm{Xie}^{b}$ \\ ${ }^{a}$ Department of Pharmacology, School of Medicine, Xi'an Jiaotong University; Xi'an 710061, China: ${ }^{b}$ Department \\ of Cell Biology and Molecular Medicine, New Jersey Medical School, University of Medicine and Dentistry of \\ New Jersey (UMDNJ); Newark, NJ 07101, U.S.A.: and ${ }^{c}$ Key Laboratory of Resource Biology and Biotechnology in \\ Western China, Ministry of Education, College of Life Sciences, Northwest University; Xi'an 710069, China. \\ Received July 25, 2012; accepted November 13, 2012; advance publication released online November 29, 2012
}

3,4,5-Trimethoxycinnamic acid (TMCA), methyl 3,4,5-trimethoxycinnamate (M-TMCA) and p-methoxycinnamic acid (PMCA) have been identified as the major bioactive components in the serum collected from rats treated with oral administration of Polygalae Radix ("YuanZhi," the roots of Polygala tenuifolia Willd.), a traditional Chinese medicine used to relieve insomnia, anxiety and heart palpitation. The present study was designed to investigate its direct electrophysiological effects on isolated ventricular myocytes from rabbits. Whole-cell configuration of the patch-clamp technique was used to measure action potential (AP) and membrane currents in single ventricular myocytes enzymatically isolated from adult rabbit hearts. $\mathrm{Ca}^{2+}$ transients were recorded in myocytes loaded with the $\mathrm{Ca}^{2+}$ indicator Fluo-4AM. Among three bioactive substances of Polygala metabolites, only M-TMCA (15-30 $\mathrm{M})$ significantly shortened action potential duration at $50 \%$ and $90 \%$ repolarization $\left(\mathrm{APD}_{50}\right.$ and $\left.\mathrm{APD}_{90}\right)$ in cardiomyocytes in a concentration-dependent and a reversible manner. M-TMCA also inhibited L-type calcium current $\left(I_{\mathrm{Ca}, \mathrm{L}}\right)$, but showed effect on neither transient outward potassium current $\left(I_{\text {to }}\right)$ nor steady-state potassium current $\left(I_{\mathrm{K}, \mathrm{Ss}}\right)$. Furthermore, M-TMCA abolished isoprenaline plus BayK8644-induced early afterdepolarizations (EADs) and suppressed delayed afterdepolarizations (DADs) and triggered activities (TAs). This potential anti-arrhythmic effects were likely attributed by the inhibition of $I_{\mathrm{Ca}, \mathrm{L}}$ and the suppression of intracellular $\mathrm{Ca}^{2+}$ transients, which consequently suppress the generation of transient inward current $\left(I_{t i}\right)$. These findings suggest that M-TMCA may protect the heart from arrhythmias via its inhibitory effect on calcium channel.

Key words methyl 3,4,5-trimethoxycinnamate; L-type calcium current; cardiomyocyte; action potential; $\mathrm{Ca}^{2+}$ transient; Polygalae Radix

Polygalae Radix (Yuan Zhi, Polygala tenuifolia WILLD.) is a well known Chinese traditional medicine used as a sedative, expectorant and tonic agent. It has been widely used to treat insomnia, anxiety, restlessness and disorientation. ${ }^{1,2)}$ The studies on the chemical components of this crude drug have demonstrated the presence of polygalitol, $\mathrm{N}$-acetyl-D-glucosamine, onjisaponins $\mathrm{A}-\mathrm{G},{ }^{3)}$ various xanthones, ${ }^{4)}$ tenuifolioses $\mathrm{A}-\mathrm{P}$, 3,4,5-trimethoxycinnamic acid (TMCA), tenuifolisides A-D and sucrose derivatives. ${ }^{5)}$ However, the main constituents in blood and bile sample of rats after oral administration of the extracts of Polygalae Radix were analyzed and showed that 3,4,5-trimethoxycinnamic acid (TMCA), methyl 3,4,5-trimethoxycinnamate (M-TMCA) and p-methoxycinnamic acid (PMCA) were its bioactive substances. ${ }^{6-9}$ ) For example, these compounds were reported to prolong sleeping time induced with hexobarbital in mice ${ }^{7)}$; TMCA exhibits anti-stress actions via the suppression of norepinephine content in rat locus coeruleus induced by corticotropin-releasing hormone. ${ }^{10)}$

In addition, Polygalae Radix was also reported to be effective in the treatment for heart palpitations. ${ }^{11)}$ Palpitations are described as unpleasant sensations of irregular and/or forceful beating of the heart, most of which are of cardiac origin although psychiatric disorders, such as anxiety, are also common causes. ${ }^{12,13)}$ Therefore, any type of tachyarrhythmias, regardless of whether or not there is an underlying structural

The authors declare no conflict of interest. or arrhythmogenic heart disease, can give rise to palpitations. Particularly, the adrenergic hyperactivation connected with intense emotions and anxiety can, in itself, predispose the patient to supraventricular and/or ventricular arrhythmias. ${ }^{14-16)}$ Thus it is apparently interesting to test whether the bioactive components (such as M-TMCA) exhibit any antiarrhythmic effects. The present study was aimed to investigate the basic electrophysiological effects of these compounds at the cellular level.

\section{MATERIALS AND METHODS}

This investigation conforms to the Guide for the Care and Use of Laboratory Animals, published by the National Institutes of Health (NIH Publication No. 85-23, Revised 1996). All animal experimental procedure were reviewed and approved by the Institutional Animal Care and Use Committee at the University of Medicine and Dentistry of New JerseyNew Jersey Medical School and by the Ethical Committee of Xi'an Jiaotong University. All experiments in single myocyte were performed at $35-37^{\circ} \mathrm{C}$.

Cell Isolation Single ventricular myocytes were enzymatically isolated from adult rabbit hearts as previously described. ${ }^{17,18)}$ Briefly, New Zealand white rabbits (male, 2 to $3 \mathrm{~kg}$ ) were anesthetized with intravenous sodium pentobarbital $(50 \mathrm{mg} / \mathrm{kg})$ after injecting heparin $(200 \mathrm{U} / \mathrm{kg}$, intravenous). The hearts were excised and perfused retrogradely in Langendorff 
fashion at $37^{\circ} \mathrm{C}$ with nominally $\mathrm{Ca}^{2+}$-free Tyrode's solution containing ca. $1.4 \mathrm{mg} / \mathrm{mL}$ collagenase (type II; Worthington, Biochemical Corp., Lakewood, NJ, U.S.A.) and $0.1 \mathrm{mg}$ / $\mathrm{mL}$ protease (type XIV, Sigma, St. Louis, MO, U.S.A.) for 25-30 min. After the enzyme solution was washed out, the hearts were removed from the perfusion apparatus and swirled in a culture dish. The $\mathrm{Ca}^{2+}$ concentration was slowly increased to $1.8 \mathrm{~mm}$, and the cells were stored at room temperature and used within $8 \mathrm{~h}$.

Patch-Clamp Methods Myocytes were patch clamped using the whole cell configuration of the patch-clamp technique in the current-clamp or voltage-clamp mode. Voltage or current signals were measured with a MultiClamp 700A patch-clamp amplifier controlled by a personal computer using a Digidata 1322 acquisition board driven by pCLAMP 10 software (Molecular Devices, Sunnyvale, CA, U.S.A.).

To record action potential (AP), patch pipettes (resistance 2 to $4 \mathrm{M} \Omega$ ) were filled with internal solution containing (in $\mathrm{mm}$ ): $110 \mathrm{~K}$-aspartate, $30 \mathrm{KCl}, 5 \mathrm{NaCl}, 10 \mathrm{~N}$-(2-hydroxyethyl)piperazine- $N^{\prime}$-2-ethanesulfonic acid (HEPES), 0.1 ethylene glycol-bis(2-aminoethylether)- $N, N, N^{\prime}, N^{\prime}$-tetraacetic acid (EGTA), 5 MgATP, $5 \mathrm{Na}_{2}$-phosphocreatine, 0.05 cAMP (pH 7.2 , adjusted with $\mathrm{KOH}$ ). Myocytes were superfused with Tyrode's solution containing (in $\mathrm{mm}$ ): $136 \mathrm{NaCl}, 4.0 \mathrm{KCl}$, $0.33 \mathrm{Na}_{2} \mathrm{PO}_{4}, 1.8 \mathrm{CaCl}_{2}, 1 \mathrm{MgCl}_{2}, 10$ glucose and 10 HEPES ( $\mathrm{pH} 7.4$, adjusted with $\mathrm{NaOH}$ ). Action potentials (APs) were elicited with 2-ms, 2- to 4-nA square pulses at a pacing cycle length (PCL) of $2 \mathrm{~s}$.

To record the $I_{\mathrm{Ca}, \mathrm{L}}$, patch pipettes were filled with internal solution containing (in $\mathrm{mm}$ ): $110 \mathrm{Cs}$-aspartate, $30 \mathrm{CsCl}$, $5 \mathrm{NaCl}, 10$ HEPES, 0.1 EGTA, $5 \mathrm{MgATP}, 5 \mathrm{Na}_{2}$-phosphocreatine, 0.05 cAMP, ( $\mathrm{pH} 7.2$, adjusted with $\mathrm{CsOH}$ ), and myocytes were perfused with a modified Tyrode's solution in which $\mathrm{KCl}$ was replaced with $\mathrm{CsCl}$. The cells were stimulated at a PCL of $2 \mathrm{~s}$ with a double-pulse protocol. Following a 100$\mathrm{ms}$ prepulse to $-40 \mathrm{mV}$ from the holding potential of $-80 \mathrm{mV}$ (to inactivate $\mathrm{Na}^{+}$current and T-type $\mathrm{Ca}^{2+}$ current), the amplitude of peak $I_{\mathrm{Ca}, \mathrm{L}}$ was elicited by a subsequent test depolarization step to $0 \mathrm{mV}$ for $500 \mathrm{~ms}$, and the current-voltage curves were elicited by voltage pulses of 500-ms duration from -40 to $50 \mathrm{mV}$ in $10-\mathrm{mV}$ steps.

To record outward $\mathrm{K}^{+}$currents, the pipette and superfusion solutions were the same as those for AP recording. Tetrodotoxin (TTX, $10 \mu \mathrm{M})$ and $\mathrm{CdCl}_{2}(0.5 \mathrm{~mm})$ were added into the Tyrode's solution to inhibit $I_{\mathrm{Na}}$ and $I_{\mathrm{Ca}, \mathrm{L}}$. Total outward $\mathrm{K}^{+}$currents were elicited by 3 -s voltage pulses from -40 to $50 \mathrm{mV}$ in $10-\mathrm{mV}$ steps at a PCL of $10 \mathrm{~s}$. The amplitudes of peak current $\left(I_{\mathrm{K}, \text { peak }}\right)$ at the beginning, and the steady state current $\left(I_{\mathrm{K}, \mathrm{SS}}\right)$ at the end of the 3-sec depolarizing pulse were evaluated.

$\mathrm{Ca}^{2+}$ Transient Measurements Myocytes were loaded with the $\mathrm{Ca}^{2+}$ indicator Fluo-4AM (Molecular Probes, Eugene, OR, U.S.A.) by incubating them for $c a .30 \mathrm{~min}$ in bath solution containing $4 \mu \mathrm{M}$ Fluo-4 AM and $0.016 \%$ pluronic (wt/wt; Molecular Probes, Sigma), after which the cells were washed and placed in a heated chamber on an inverted microscope. $\mathrm{Ca}^{2+}$ fluorescence was excited at $485 \mathrm{~nm}$ and the emission measured at $515 \mathrm{~nm}$. The fluorescence was monitored using a Nikon Eclipe TE200 inverted microscope with a Fluor x40 oil objective lens (numerical aperture 1.3) and recorded using an Andor Ixon Charge-Coupled Device (CCD) camera (Andor Technology) operating with Imaging Workbench software
(INDEC BioSystems) at ca. 100 frames per second with a spatial resolution of $500 \times 400$ pixels. Fluorescence intensity was recorded as the ratio $F / F_{0}$ of the fluorescence $(F)$ over the basal diastolic fluorescence $\left(F_{0}\right)$.

Chemicals TMCA, PMCA and M-TMCA were obtained from Meryer Chemical Technology Co., Ltd. (Shanghai, China). They were dissolved in dimethylsulfoxide (DMSO) as stock solution $(50 \mathrm{~mm})$ before adding to the bath Tyrode's solution at the final concentration. The maximum DMSO concentration was $<0.2 \%$ ( $\mathrm{vol} / \mathrm{vol}$ ). Other chemicals and reagents were purchased from Sigma Chemical Co. (St. Louis, MO, U.S.A.) unless indicated. All experiments on single myocyte in the present study were carried out at $35-37^{\circ} \mathrm{C}$.

Statistical Analysis Data are shown as mean \pm S.D. Statistical differences were evaluated using Student's paired or unpaired $t$-tests or Fisher's exact test, with $p<0.05$ considered as statistically significant.

\section{RESULTS}

The Effect of TMCA, PMCA and M-TMCA on APs in Rabbit Ventricular Myocytes We first investigated the effects of TMCA, PMCA and M-TMCA on APs in isolated rabbit ventricular myocytes. As shown in Fig. 1, only M-TMCA significantly attenuated action potential duration (APD) in a reversible and concentration-dependent manner (at 15, 30 $\mu \mathrm{M}$ ) (Figs. 1C, Dc), while TMCA and PMCA did not show any effect (Figs. 1A,B) at either the same concentrations or a higher concentration $(50 \mu \mathrm{M})$. The decrease of APD appeared at $30 \mathrm{~s}-1 \mathrm{~min}$ after the application of M-TMCA and reached a steady state at 3-4 min. M-TMCA (30 $\mu \mathrm{M})$ significantly reduced $\mathrm{APD}$ at $50 \%$ and $90 \%$ repolarization $\left(\mathrm{APD}_{50}\right.$, $\mathrm{APD}_{90}$ ) from $219.1 \pm 15.7$ and $292.4 \pm 17.3 \mathrm{~ms}$ to $184.5 \pm 16.2$ and $240.6 \pm 18.5 \mathrm{~ms}$, respectively, (Figs. $1 \mathrm{Db}, \mathrm{Dc} ; n=6, p<0.01$ ), while the resting membrane potential (RMP), action potential amplitude (APA) and APD at 20\% repolarization $\left(\mathrm{APD}_{20}\right)$ were not changed (Figs. 1C, Da).

The Inhibitory Effect of M-TMCA on L-Type Calcium Current Since M-TMCA reduced $\mathrm{APD}_{50}$, but not $\mathrm{APD}_{20}$ in rabbit myocytes, we assumed this effect was most likely due to its inhibition on $I_{\mathrm{Ca}, \mathrm{L}}$. In the following experiments, we recorded whole-cell $I_{\mathrm{Ca}, \mathrm{L}}$ from rabbit ventricular myocytes. As shown in Fig. 2, M-TMCA $(30 \mu \mathrm{M})$ reduced the amplitude of $I_{\mathrm{Ca}, \mathrm{L}}$ at $0.5-1 \mathrm{~min}$ after exposure and reached the steady state at 2-3 min (Fig. 2A). Similarly, the inhibitory effect of M-TMCA on $I_{\mathrm{Ca}, \mathrm{L}}$ was reversible and concentration-dependent (Figs. 2A, Ba). The mean peak amplitude of $I_{\mathrm{Ca}, \mathrm{L}}($ at $0 \mathrm{mV}$ ) was pronouncedly decreased by $15.2 \pm 3.6 \%$ from $11.2 \pm 1.1$ to $9.2 \pm$ $0.9 \mathrm{pA} / \mathrm{pF}$ at $15 \mu \mathrm{M}(n=8, p<0.05)$ and by $30.3 \pm 6.5 \%$ to $7.8 \pm$ $1.3 \mathrm{pA} / \mathrm{pF}$ at $30 \mu \mathrm{M}(n=5, p<0.01)$. The current-voltage relations for the peak current (Fig. 2Bb) showed that the $I_{\mathrm{Ca}, \mathrm{L}}$ amplitude was significantly attenuated at testing potentials -10 to $+40 \mathrm{mV}$, without any significant voltage shift by M-TMCA.

The Effect of M-TMCA on $\mathbf{C a}^{2+}$ Transients Since the alteration of $I_{\mathrm{Ca}, \mathrm{L}}$ would affect $\mathrm{Ca}^{2+}$ transient in myocytes, we further investigated the effect of M-TMCA on $\mathrm{Ca}^{2+}$ transient. Cells were first paced at a PCL of $2 \mathrm{~s}$ under field stimulation. After $\mathrm{Ca}^{2+}$ transient reached steady state, cells were perfused with M-TMCA at 5, 15 and $30 \mu \mathrm{M}$, respectively, for $c a$. $5 \mathrm{~min}$. M-TMCA concentration-dependently decreased the magnitudes of $\mathrm{Ca}^{2+}$ transient (Figs. 3Aa, b). The mean amplitude of 

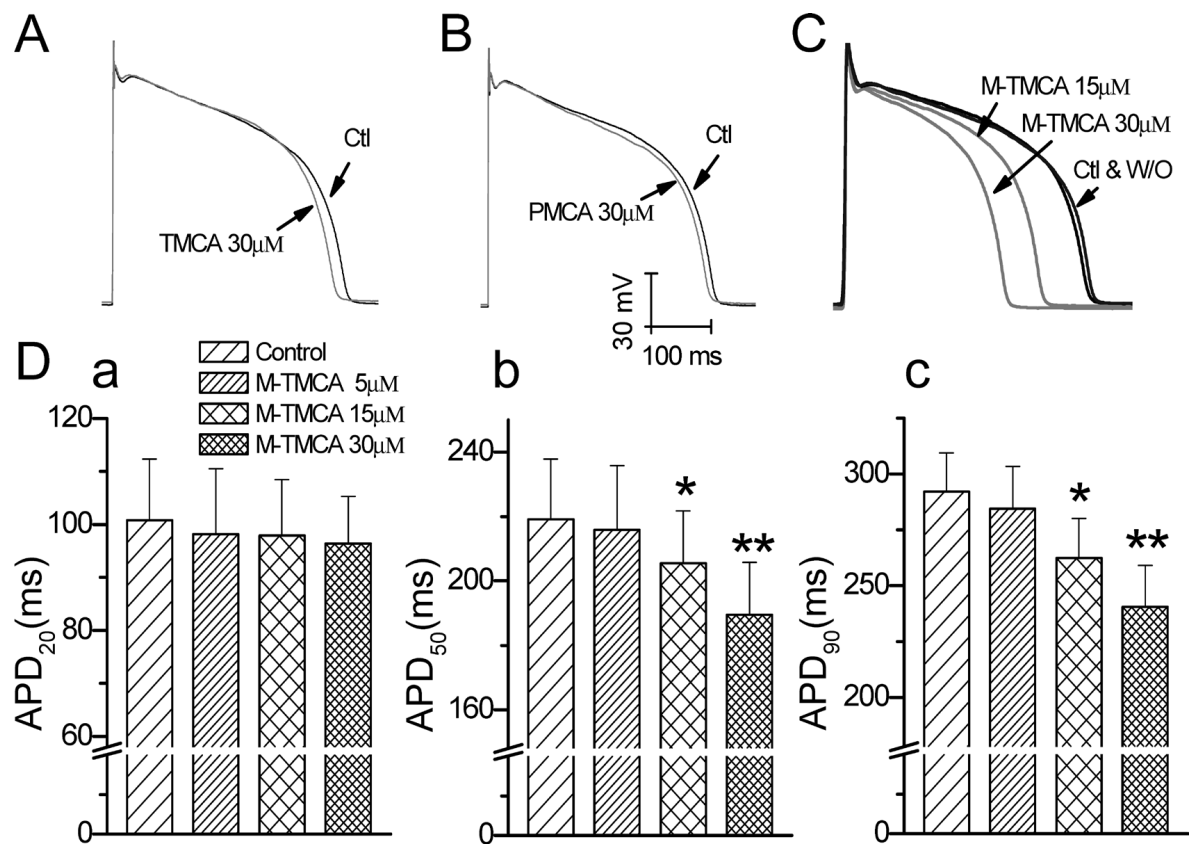

Fig. 1. The Effects of TMCA, PMCA and M-TMCA on Action Potentials (AP) in Rabbit Ventricular Myocytes

Representative AP traces in the absence and presence of $30 \mu \mathrm{M} \mathrm{TMCA} \mathrm{(A),} 30 \mu \mathrm{M}$ PMCA (B), and 15, 30 $\mu \mathrm{M}$ M-TMCA and wash out (washing for 2 min) (C) were recorded from three different ventricular myocytes. (D) a-c: Summarized bar graphs showing concentration-dependent shortening effects of M-TMCA on action potential duration at $20 \%, 50 \%$ and $90 \%$ repolarization $\left(\mathrm{APD}_{20}, \mathrm{APD}_{50}\right.$, and $\left.\mathrm{APD}_{90}\right) . *{ }^{*}<0.05, * * p<0.01$ vs. control, $n=6$.

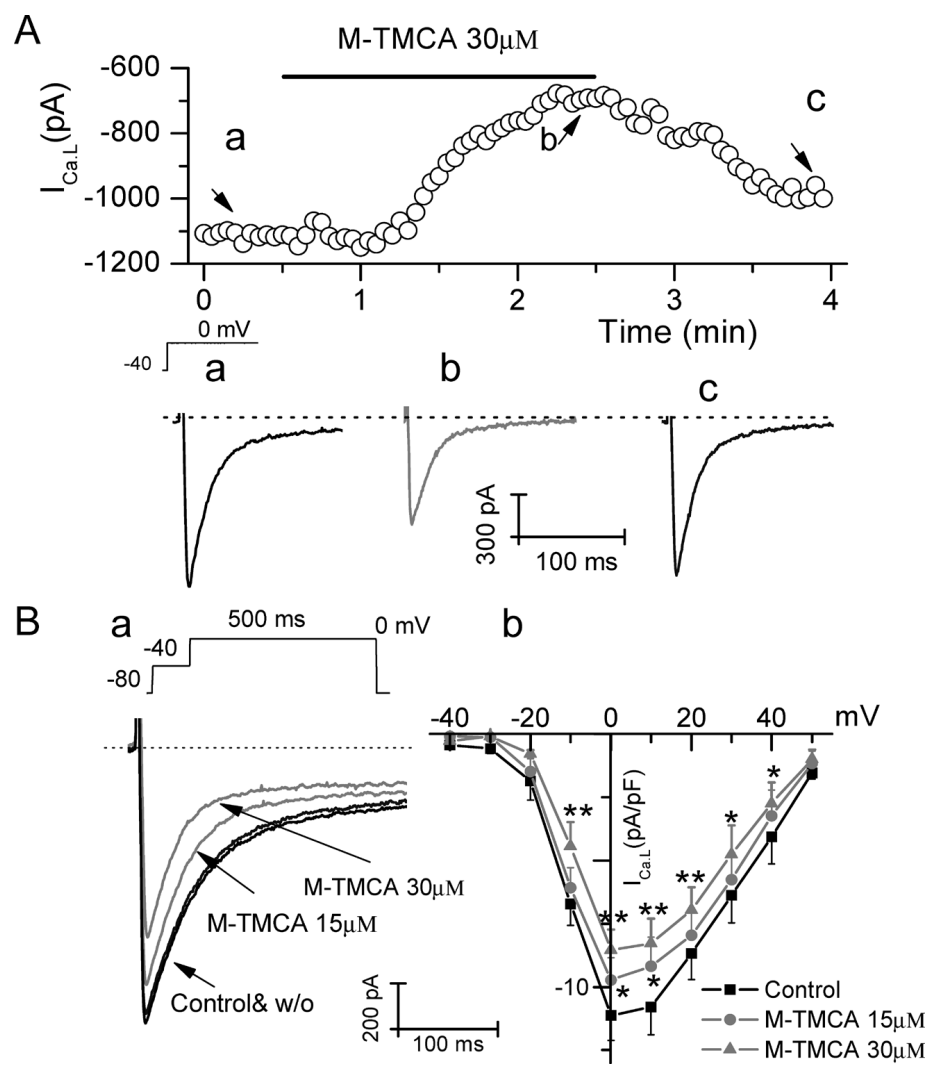

Fig. 2. Inhibition of $I_{\mathrm{Ca}, \mathrm{L}}$ by M-TMCA

(A) Time course of peak $I_{\mathrm{CaI}}$ recorded from a myocyte treated with $30 \mu \mathrm{M}$ M-TMCA. Representative traces of $I_{\mathrm{CaI}}$ corresponding to points a-c are shown under the plot. (Ba) Representative traces of $I_{\mathrm{Ca}, \mathrm{L}}$ (elicited with a test potential at $0 \mathrm{mV}$ ) under control condition, in the presence of $15,30 \mu \mathrm{M}$ M-TMCA and after washout of M-TMCA, respectively. (Bb) The current-voltage relations for $I_{\mathrm{Ca}, \mathrm{L}}$ under control condition, in the presence of 15 and $30 \mu \mathrm{M} \mathrm{M}-\mathrm{TMCA}$. ${ }^{*} p<0.05,{ }^{* *} p<0.01 v s$. control $(n=8)$.

$\mathrm{Ca}^{2+}$ transient was significantly reduced from $F / F_{0}=1.50 \pm 0.27$

(Control) to $1.31 \pm 0.15(15 \mu \mathrm{M}$ M-TMCA, $n=6, p<0.05)$ and to $1.24 \pm 0.08(30 \mu \mathrm{M}$ M-TMCA, $n=6, p<0.01)$, respectively.
Furthermore, we also observed the effect of M-TMCA on the staircase of $\mathrm{Ca}^{2+}$ transient in rabbit myocytes. After $\mathrm{Ca}^{2+}$ transient reached steady state, cells were paced with field 


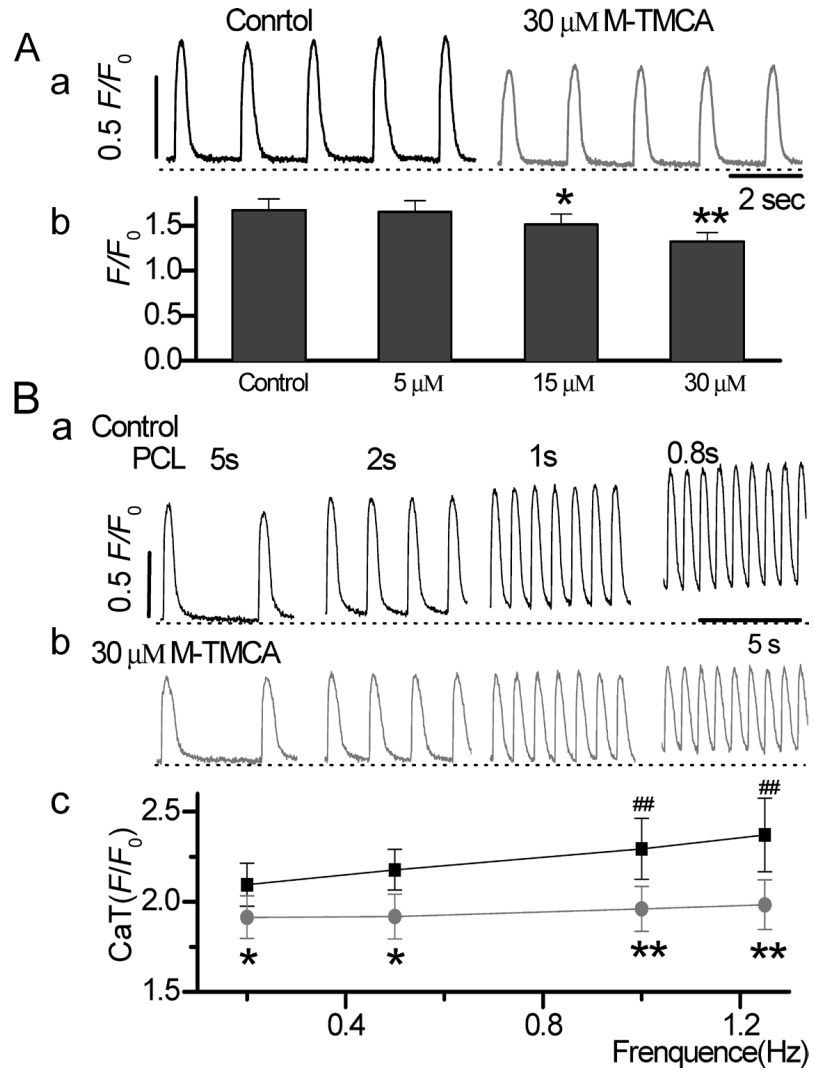

Fig. 3. Inhibitory Effects of M-TMCA on $\mathrm{Ca}^{2+}$ Transients and Positive Staircase of $\mathrm{Ca}^{2+}$ Transients

(Aa) Representative $\mathrm{Ca}^{2+}$ transient traces recorded from a myocyte in the absence or presence of $30 \mu \mathrm{M}$ M-TMCA ( 3 min after perfusion). (Ab) $\mathrm{Ca}^{2+}$ transients were elicited by field stimulation at a pace cycle length (PCL) of $2 \mathrm{~s}$. A summarized bar graph showing the concentration-dependent decreases of $\mathrm{Ca}^{2+}$ transients induced by M-TMCA. $* p<0.05, * * p<0.01$ vs. control, $n=6$. (Ba) Under control condition, a positive staircase of $\mathrm{Ca}^{2+}$ transients was observed. (Bb) Suppression of the positive staircase in the presence of $30 \mu \mathrm{M}$ M-TMCA. $\mathrm{Ca}^{2+}$ transients were elicited by field stimulation at PCLs of 5,2,1,0.8 s, respectively, as indicated. Calcium fluorescence intensity was recorded as the ratio $F / F_{0}$ (i.e. the fluorescence $(F)$ over the basal diastolic fluorescence $\left(F_{0}\right)$ at PCL of $5 \mathrm{~s}$ ). (Bc) Summarized data $(n=7)$ for $\mathrm{Ca}^{2+}$ transient amplitude in the absence or presence of M-TMCA. In the absence of M-TMCA: \# ${ }^{\#}<0.01$ compared to control value at PCL of $5 \mathrm{~s}$. In the presence of M-TMCA: $* p<0.05, * * p<0.01$ compared to those in the absence of M-TMCA at each PCL.

stimulation at consecutive PCLs of $5 \mathrm{~s}, 2 \mathrm{~s}, 1 \mathrm{~s}$, and $0.8 \mathrm{~s}$. As shown in Figs. $3 \mathrm{Ba}-\mathrm{c}$, a positive staircase was observed under control condition, whereas in the presence of $30 \mu \mathrm{M}$ M-TMCA the $\mathrm{Ca}^{2+}$ transients were reduced and the positive staircase phenomenon was suppressed.

The Inhibitory Effect of M-TMCA on Afterdepolarizations The early afterdepolarization (EAD), delayed afterdepolarization (DAD) and triggered activity (TA) are major causes for arrhythmias. The increase or reactivation of $I_{\mathrm{Ca}, \mathrm{L}}$ has been identified to contribute to the generation of afterdepolarizations, while the inhibition of $I_{\mathrm{Ca}, \mathrm{L}}$ suppresses the incidence of EADs and TAs in isolated myocytes. Next, we further investigated the effect of M-TMCA on afterdepolarizations induced under $\mathrm{Ca}^{2+}$ overloaded condition (by Isoprenaline and BayK8644) in ventricular myocytes as we previous reported. ${ }^{19)}$ APs were recorded at a PCL of $2 \mathrm{~s}$. As shown in Fig. 4A, there is no EAD, DAD or TA observed under control condition (Fig. 4Aa). Exposure of isoprenaline (100 nM) plus BayK8644 (50 nm) (Iso/BayK) for 2-3 min consistently caused EADs, DADs or TAs (Fig. 4Ab). Treatment of $30 \mu \mathrm{M}$ M-TMCA for $3 \mathrm{~min}$ in myocytes significantly shortened Iso/
BayK-induced prolongation of APD, completely abolished EADs and TAs (Figs. 4Ac,d). In the presence of M-TMCA $(30 \mu \mathrm{M})$, the incidence of EAD by counting the number of EADs within 20 consecutive APs was lowered from 95 \pm 4.5 to $0 \%(n=5, p<0.01)$, the number of DADs or TAs was suppressed from $48 \pm 5.9$ to $1 \pm 1.2 \%(n=6, p<0.01)$. In addition, M-TMCA $(30 \mu \mathrm{M})$ markedly attenuated the increases of $I_{\mathrm{Ca}, \mathrm{L}}$ amplitude (at $0 \mathrm{mV}$ ) induced by Iso/BayK from $28.3 \pm 5.9$ to $18.9 \pm 3.8 \mathrm{pA} / \mathrm{pF}(n=5, p<0.01)$. The transient inward currents $\left(I_{\mathrm{ti}}\right)$ induced by Iso/BayK were also eliminated from 0.94士 0.08 to $0.02 \pm 0.01 \mathrm{pA} / \mathrm{pF}(n=5, p<0.01)$ (Figs. $5 \mathrm{~A}, \mathrm{Ba}, \mathrm{b})$.

Little Effect of M-TMCA on Outward $\mathrm{K}^{+}$Currents Since the reduction of APD may be also attributed to an increase in outward $\mathrm{K}^{+}$currents, we next evaluated the effects of M-TMCA on total outward $\mathrm{K}^{+}$currents. As shown in Fig. 6 , the current-voltage curves were elicited by voltage pulses of 3 -s duration from -40 to $50 \mathrm{mV}$ in $10-\mathrm{mV}$ steps. Neither peak $\left(I_{\mathrm{K}, \text { peak }}\right)$ (Control: 12.5 \pm 1.7 vs. M-TMCA: $11.7 \pm 1.4 \mathrm{pA} /$ $\mathrm{pF}, n=7, p>0.05)$ nor steady state $\left(I_{\mathrm{K}, \mathrm{SS}}\right)$ (Control: $2.4 \pm 0.3 \mathrm{vs}$. M-TMCA: $2.6 \pm 0.4 \mathrm{pA} / \mathrm{pF}, n=7, p>0.05)$ outward potassium currents were significantly altered by M-TMCA at the concentration of $30 \mu \mathrm{M}$ that significantly reduced APD under current clamp condition.

\section{DISCUSSION}

TMCA, PMCA and M-TMCA have been shown to produce sedative effects and prolong sleeping time in mice, ${ }^{7,8)}$ but their cardiovascular effects remain unclear. In the present study, we have investigated the electrophysiological effects of the bioactive substances of traditional Chinese medicine Polygalae Radix on rabbit ventricular myocytes. The major findings are: 1) Among the three bioactive substances of Polygala metabolites, (TMCA, M-TMCA, and PMCA), only M-TMCA exhibits significantly electrophysiological effects on isolated rabbit ventricular myocytes; 2) M-TMCA significantly shortens APD of cardiomyocytes in a concentration-dependent and a reversible manner, which are mainly mediated by the inhibition of $I_{\mathrm{Ca}, \mathrm{L}}$; 3) M-TMCA inhibites the intracellular $\mathrm{Ca}^{2+}$ transient and suppresses $I_{\mathrm{ti}}$ induced by Iso/BayK. 4) M-TMCA suppresses EADs, DADs and TAs induced by Iso/BayK and thus may have antiarrhythmic potentials.

Our results showed that M-TMCA concentration-dependently shortened $\mathrm{APD}_{50}$ and $\mathrm{APD}_{90}$. $\mathrm{APDD}_{20}$ represents the early phase of action potential repolarization in cardiomyocytes and the fast $I_{\text {to }}$ predominately contributes to this repolarizing process. Our results showed that M-TMCA had no significant effect on $\mathrm{APD}_{20}$ (Fig. 1), consistent with the result that $\mathrm{M}$ TMCA did not affect fast $I_{\text {to }}$ (Fig. 6A). The shortenings of $\mathrm{APD}_{50}$ and $\mathrm{APD}_{90}$ may implicate a decrease in inward currents $\left(\right.$ e.g. $\left.I_{\mathrm{Ca}, \mathrm{L}}\right)$ or an increase in outward currents (e.g. $\left.I_{\mathrm{K}}\right)$ in the process of cardiomyocyte repolarization. The present study demonstrated that M-TMCA rapidly inhibited $I_{\mathrm{Ca}, \mathrm{L}}$ in ventricular myocytes, consistent with the time course for $\mathrm{APD}_{90}$ shortening (Fig. 1A). However, M-TMCA at $30 \mu \mathrm{M}$, the concentration which dramatically shortened APD and suppressed $I_{\mathrm{Ca}, \mathrm{L}}$, did not show any alteration in $I_{\mathrm{K}, \mathrm{SS}}$ (Fig. 6). We further showed that M-TMCA inhibited $\mathrm{Ca}^{2+}$ transient in a concentration-dependent manner and abolished the positive staircase effect of $\mathrm{Ca}^{2+}$ transient in single isolated cardiac myocytes (Fig. 3). It has been suggested that frequency-dependent 


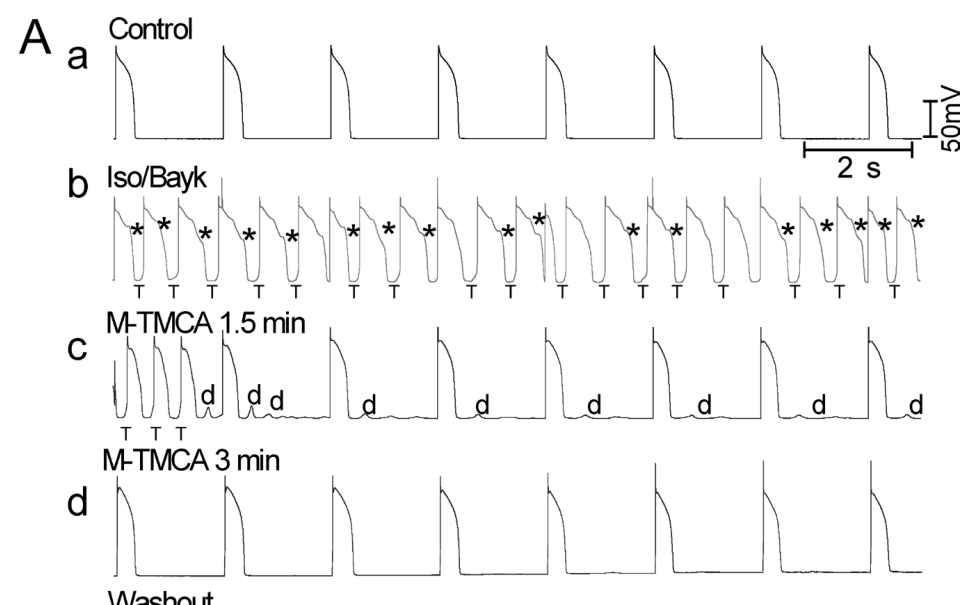

e
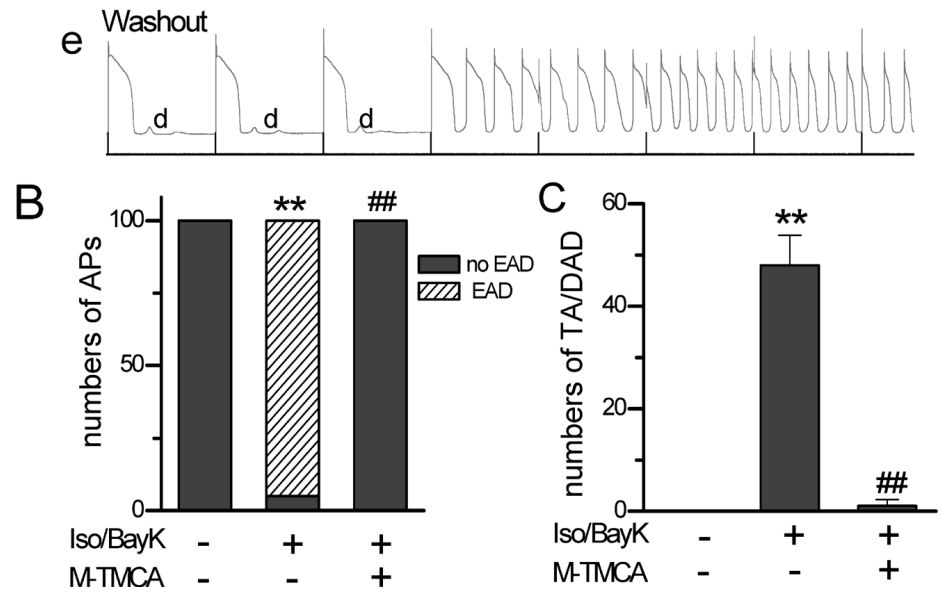

Fig. 4. Inhibitory Effects of M-TMCA on Early Afterdepolarizations (EADs), Delayed Afterdepolarizations (DADs), and Triggered Activities (TAs)

(A) Eight consecutive action potentials (APs) recorded from a cell exposed to control perfusate (Aa), 100nm Isoprenaline plus 50 nM BayK8644 (Iso/BayK) (Ab), Iso/ BayK and $30 \mu \mathrm{M}$ M-TMCA treatment for $1.5 \mathrm{~min}(\mathrm{Ac})$, Iso/BayK and $30 \mu \mathrm{M} \mathrm{M}-\mathrm{TMCA}$ treatment for $3 \mathrm{~min}(\mathrm{Ad})$, as well as after washout of M-TMCA (Ae). EADs $(*)$, DADs (d) and triggered AP (T) are indicated. (B) Bar graphs summarizing the inhibitory effects of M-TMCA on Iso/BayK-induced incidences of EADs (Ba) and DADs/TAs (Bb) within $20 \mathrm{APs}(n=5) . * * p<0.01$, compared to control, ${ }^{\# \#} p<0.01$, compared to Iso+BayK group. Fisher's exact test was used.

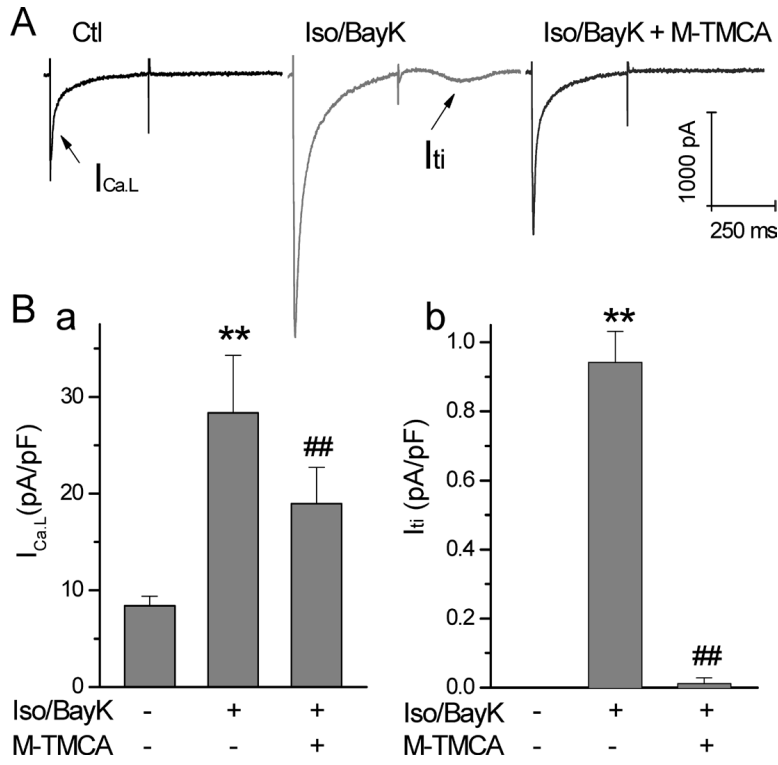

Fig. 5. Inhibitory Effects of M-TMCA on Iso/BayK-Induced Augment of $I_{\mathrm{Ca}, \mathrm{L}}$ and $I_{\mathrm{ti}}$

(A) Representative traces of $I_{\mathrm{C}, L}$ recorded from a cell perfused with control perfusate, $100 \mathrm{~nm}$ Iso plus $50 \mathrm{~nm}$ BayK8644 (Iso/BayK) and Iso/BayK $+30 \mu \mathrm{M}$ M-TMCA, respectively. (B) Bar graphs summarizing the inhibitory effects of M-TMCA on Iso/BayK-induced enhancement of $I_{\mathrm{Ca}, \mathrm{L}}(\mathrm{Ba})$ and $I_{\mathrm{ti}}(\mathrm{Bb})(n=5)$. ${ }_{*}^{*} p<0.01$, compared to control, ${ }^{\# \#} p<0.01$, compared to to Iso+BayK group. potentiation of $I_{\mathrm{Ca}, \mathrm{L}}$ might be an important mechanism underlying positive staircase in cardiomyocytes..$^{20,21)}$ It has been evidenced that positive staircase is characterized mainly by an increase in peak current amplitude or slowing inactivation of $I_{\mathrm{Ca}, \mathrm{L}}$ kinetics. ${ }^{22)}$ Blocking $I_{\mathrm{Ca}, \mathrm{L}}$ (e.g., verapamil, nifedipine) eliminated the positive staircase of contraction in cardiomyocytes. ${ }^{23)}$ Our results revealed that M-TMCA significantly suppressed the amplitude of $I_{\mathrm{Ca}, \mathrm{L}}$ and $\mathrm{Ca}^{2+}$ transient, suggesting that the inhibitory effect of M-TMCA on peak $I_{\mathrm{Ca}, \mathrm{L}}$ plays a critical role in the elimination of the pos6itive staircase of $\mathrm{Ca}^{2+}$ transient in rabbit ventricular myocytes.

It was reported that onjisaponin $\mathrm{E}, \mathrm{F}$ and $\mathrm{G}$ in water extract of Radix Polygalae inhibited cAMP phosphodiesterase using an in vitro screening method, ${ }^{24)}$ which might cause alterations of cAMP metabolism. Although onjisaponin E, F and G, sucrose derivatives and others containing 3,4,5,-trimethoxycinnamoyl moiety within their chemical structures in Polygalae Radix were metabolized to TMCA and M-TMCA in rat gastrointestinal tract and liver, ${ }^{7)}$ it is not known whether MTMCA itself has the same effect in cardiac myocytes so far. Since our results show that M-TMCA suppresses $I_{\mathrm{Ca}, \mathrm{L}}$ and decreases $\mathrm{Ca}^{2+}$ transients, we assume that M-TMCA should play less effect on phosphodiesterase inhibition in cardiomyocytes. Further studies are needed to clarify this point.

Polygala, often used as a sedative agent, is also applied in the treatment for heart palpitations in traditional Chinese 

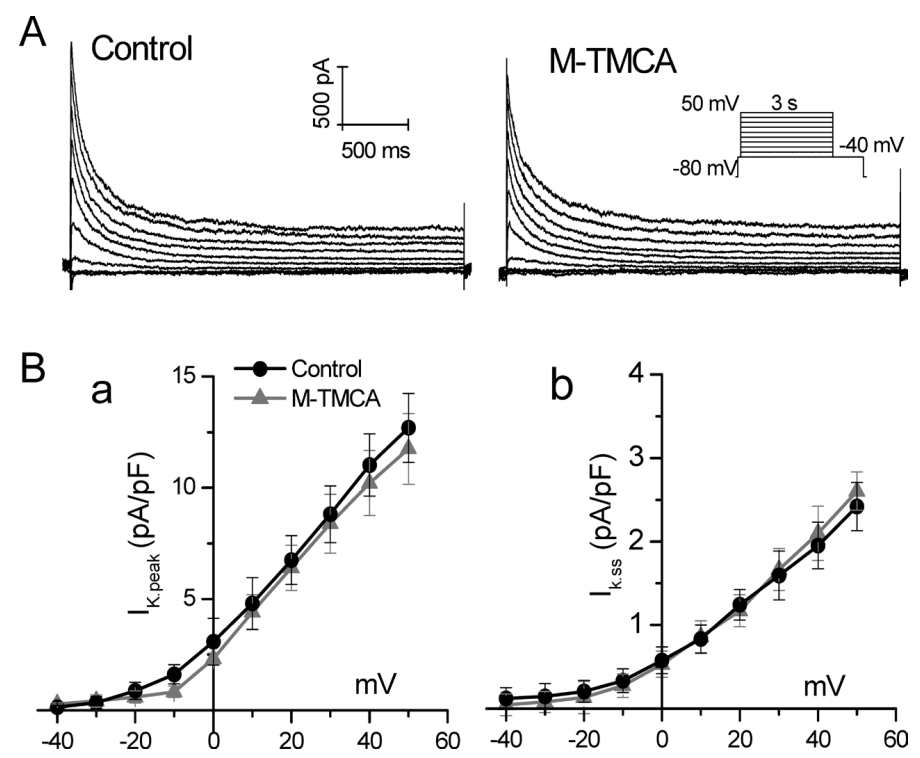

Fig. 6. Little Effect of M-TMCA on Transient Outward $\mathrm{K}^{+}$Current $\left(I_{\mathrm{to}}\right)$ and Steady-State Currents $\left(I_{\mathrm{K}, \mathrm{SS}}\right)$

(A) Original current traces in the absence (control) and presence of $30 \mu \mathrm{M}$ M-TMCA (M-TMCA). Test potentials ranged from -40 to $+50 \mathrm{mV}$ in $10 \mathrm{mV}$ steps (protocol shown in inset). (B) Current-voltage relations of averaged peak $I_{\mathrm{to}}(\mathrm{Ba})$ and steady-state currents $\left(I_{\mathrm{K}, \mathrm{Ss}}\right.$, Bb) showing little effects of M-TMCA on $I_{\mathrm{to}}$ and $I_{\mathrm{K}, \mathrm{sS}}(n=5)$.

medical practice. Strictly, a palpitation is an abnormality of heartbeat that ranges from often unnoticed skipped beats or accelerated heart rates to very noticeable changes. Based on our previous studies, ${ }^{19)}$ therefore, we investigated the effects of M-TMCA on Iso/BayK-induced EADs, DADs, and TAs, which are triggers for arrhythmias at single cell level. Both Iso and BayK potentiate $I_{\mathrm{Ca}, \mathrm{L}}$. It has been shown that reactivation of $I_{\mathrm{Ca}, \mathrm{L}}$ is implicated in EAD generation. ${ }^{25)}$ Furthermore, enhanced $I_{\mathrm{Ca}, \mathrm{L}}$ may lead to $\mathrm{Ca}^{2+}$ overload, which consequently results in DADs. In addition, BayK also causes SR $\mathrm{Ca}^{2+}$ leaking. ${ }^{26)}$ These effects further induce spontaneous SR $\mathrm{Ca}^{2+}$ waves, and subsequently cause DADs and TAs by activating $I_{\mathrm{ti}}$ due to electrogenic $\mathrm{Na}^{+}-\mathrm{Ca}^{2+}$ exchange current. ${ }^{26,27)}$ We found that $30 \mu \mathrm{M}$ M-TMCA abolished Iso/BayK-induced EADs and significantly reduced the occurrence of DADs and TAs (Fig. 4). Previous studies by our group and others have documented that selective calcium channel blockers (e.g. nifedipine) effectively suppress EADs and DADs in various models. ${ }^{19,28)}$ Consistent with these findings, the suppression of EADs, DADs, and TAs by M-TMCA is most likely mediated by its inhibitory effect on $I_{\mathrm{Ca}, \mathrm{L}}$. Since the synergistic interactions between $I_{\mathrm{Ca}, \mathrm{L}}$ and $I_{\mathrm{ti}}$ play important roles in EAD generation in the Iso/BayK model, ${ }^{19)}$ M-TMCA significantly inhibited the augmentation of $I_{\mathrm{Ca}, \mathrm{L}}$ induced by $\mathrm{Iso} / \mathrm{BayK}$, and thereby reduced $\mathrm{Ca}^{2+}$ influx and SR $\mathrm{Ca}^{2+}$ overload, which account for the suppression of subsequent generation of $I_{\mathrm{ti}}$ and EADs, DADs and TAs. It should be noted that we cannot exclude the possibility that MTMCA may antagonize the $\beta$-adrenergic effects via the direct blockage of $\beta$-adrenergic receptors, which may also suppress the EADs, DADs and TAs induced by Iso/BayK.

To our knowledge, there is no report on the plasma concentrations of M-TMCA in human subjects who take Polygalae Radix. However, it has been reported that the plasma concentration of M-TMCA is $c a$. $1-2 \mu \mathrm{g} / \mathrm{mL}$ (equivalent to $c a$. $4-8 \mu \mathrm{M})$ in rats with single oral administration of water extract of Polygalae Radix $(5-10 \mathrm{~g} / \mathrm{kg}$ ), and is $c a$. $7-8 \mu \mathrm{g} / \mathrm{mL}$ (equivalent to $c a .28-32 \mu \mathrm{M}$ ) in rats with intravenous administration of M-TMCA $(10 \mathrm{mg} / \mathrm{kg}){ }^{7,8)}$ We assume that the steady-state plasma concentration of M-TMCA after repetitive administrations would reach the level that is close to its effective concentration range $(>10 \mu \mathrm{M})$ for the inhibition of $I_{\mathrm{Ca}, \mathrm{L}}$ and potential suppression of arrhythmias.

Calcium channel blockers (e.g. verapamil) are used as class IV antiarrhythmic drugs in clinic. Since they preferentially affect the rate of slow response myocardial tissue (i.e. the sinoatrial and atrioventricular nodes), calcium channel blockers have been primarily used in the management of certain arrhythmias such as supraventricular tachyarrhythmias associated with atrioventricular nodal reentrant tachycardia, ${ }^{29)}$ as well as in the rate control for atrial fibrillation. ${ }^{30)}$ It has also been demonstrated that calcium channel blockers suppress EADs, DAD, and TAs, ${ }^{19,28)}$ suggesting class IV drugs may be effective in treating afterdepolarization-induced triggered arrhythmias. For example, verapamil is capable of preventing ischemic and reperfusion arrhythmias. ${ }^{31)}$ M-TMCA, which exhibits L-type calcium channel inhibitory effect, should also be effective in treating these types of arrhythmias (i.e. supraventricular tachyarrhythmias and triggered ventricular arrhythmias) in clinic setting. This notion was supported by the result showing M-TMCA suppressed Iso/BayK-induced EADs, DAD and TAs in isolated myocytes (Fig. 4). Further experiments are needed to fully demonstrate the antiarrhythmic properties of M-TMCA in intact animal models.

Acknowledgements This work was supported by the National Natural Science Foundation of China (81170597) and the Natural Science Foundation of Shaanxi Province (SJ08C223).

\section{REFERENCES}

1) Yao Y, Jia M, Wu JG, Zhang H, Sun LN, Chen WS, Rahman K. Anxiolytic and sedative-hypnotic activities of polygalasaponins from Polygala tenuifolia in mice. Pharm. Biol., 48, 801-807 (2010).

2) Willow M, Carmody J, Carroll P. The effects of swimming in mice on pain perception and sleeping time in response to hypnotic drugs. Life Sci., 26, 219-224 (1980). 
3) Sakuma S, Shoji J. Studies on the constituents of the root of Polygala tenuifolia WiLLDENOW.II. on the structures of onjisaponins A, B and E. Chem. Pharm. Bull., 30, 810-821 (1981).

4) Ikeya Y, Sugama K, Maruno M. Xanthone C-glycoside and acylated sugar from Polygala tenuifolia. Chem. Pharm. Bull., 42, 2305-2308 (1994).

5) Ikeya Y, Sugama K, Okada M, Mitsuhashi H. Two xanthones from Polygala tenuifolia. Phytochemistry, 30, 2061-2065 (1991).

6) Komatsu K, Wakame K, Kano Y. Pharmacological properties of galenical preparation. XVI. Pharmacokinetics of evodiamine and the metabolite in rats. Biol. Pharm. Bull., 16, 935-938 (1993).

7) Wang S, Kozuka K, Saito K, Kano Y. Pharmacological properties of galenical preparations (XVII): Active compounds in blood and bile of rats after oral administrations of extracts of Polygalae Radix. J. Trad. Med., 11, 44-49 (1994).

8) Wang S, Kozuka K, Saito K, Komatsu K, Kano Y. Pharmacological properties of galenical preparations (XVIII): Pharmacokinetics of action compounds of Polygalae Radix. J. Trad. Med., 11, 168-175 (1994).

9) Wang S, Saito K, Owada E, Kano Y. Pharmacological properties of galenical preparations (XX): Screening of natural prodrugs in Polygalae Radix. J. Trad. Med., 12, 102-108 (1995).

10) Kawashima K, Miyako D, Ishino $Y$, Makino T, Saito K, Kano Y. Anti-stress effects of 3,4,5-trimethoxycinnamic acid, an active constituent of roots of Polygala tenuifolia (ONJI). Biol. Pharm. Bull., 27, 1317-1319 (2004).

11) Chang HM, But PP-H. "Pharmacology and applications of Chinese material medica," Vol. 1, ed. by World Scientific Publishing, Singapore, pp. 551-553 (1986)

12) Wexler RK, Pleister A, Raman S. Outpatient approach to palpitations. Am. Fam. Physician, 84, 63-69 (2011).

13) Reagan BW, Huang RL, Clair WK. Palpitations: an annoyance that may require clairvoyance. Circulation, 125, 958-965 (2012).

14) Nyrnes A, Mathiesen EB, Njølstad I, Wilsgaard T, Løchen ML. Palpitations are predictive of future atrial fibrillation. An 11-year follow-up of 22,815 men and women: the Tromso Study. Eur. J. Prev. Cardiol. (2012) May 15. [Epub ahead of print].

15) Lampert R, Joska T, Burg MM, Batsford WP, McPherson CA, Jain D. Emotional and physical precipitants of ventricular arrhythmia. Circulation, 106, 1800-1805 (2002).

16) Ziegelstein RC. Acute emotional stress and cardiac arrhythmias. JAMA, 298, 324-329 (2007).

17) Xie LH, Weiss JN. Arrhythmogenic consequences of intracellular calcium waves. Am. J. Physiol. Heart Circ. Physiol., 297, H997H1002 (2009).
18) Zhao Z, Fefelova N, Shanmugam M, Bishara P, Babu GJ, Xie LH. Angiotensin II induces afterdepolarizations via reactive oxygen species and calmodulin kinase II signaling. J. Mol. Cell. Cardiol., 50, 128-136 (2011).

19) Zhao Z, Wen H, Fefelova N, Allen C, Baba A, Matsuda T, Xie LH. Revisiting the ionic mechanisms of early afterdepolarizations in cardiomyocytes: predominant by $\mathrm{Ca}$ waves or Ca currents? Am. J. Physiol. Heart Circ. Physiol., 302, H1636-H1644 (2012).

20) Palomeque J, Vila Petroff MG, Mattiazzi A. Pacing staircase phenomenon in the heart: from Bodwitch to the XXI century. Heart Lung Circ., 13, 410-420 (2004).

21) Endoh M. Force-frequency relationship in intact mammalian ventricular myocardium: physiological and pathophysiological relevance. Eur. J. Pharmacol., 500, 73-86 (2004).

22) Richard S, Perrier E, Fauconnier J, Perrier R, Pereira L, Gõmez AM, Bénitah JP. ' $\mathrm{Ca}^{2+}$-induced $\mathrm{Ca}^{2+}$ entry' or how the L-type $\mathrm{Ca}^{2+}$ channel remodels its own signalling pathway in cardiac cells. Prog. Biophys. Mol. Biol., 90, 118-135 (2006).

23) Brotto MA, Creazzo TL. Ca2+ transients in embryonic chick heart: contributions from $\mathrm{Ca}^{2+}$ channels and the sarcoplasmic reticulum. Am. J. Physiol., 270, H518-H525 (1996).

24) Nikaido T, Ohmoto T, Saitoh H, Sankawa U, Sakuma S, Shoji J. Inhibitors of cyclic adenosine monophosphate phosphodiesterase in Polygala tenuifolia. Chem. Pharm. Bull., 30, 2020-2024 (1982).

25) January CT, Riddle JM. Early afterdepolarizations: mechanism of induction and block. A role for L-type $\mathrm{Ca}^{2+}$ current. Circ. Res., 64, 977-990 (1989).

26) Mackiewicz U, Emanuel K, Lewartowski B. Agonist of dihydropyridine receptors, BayK8644 depresses excitation-contraction coupling in myocytes of guinea pig heart. J. Physiol. Pharmacol., 52, 459-469 (2001).

27) Sung RJ, Lo CP, Hsiao PY, Tien HC. Targeting intracellular calcium cycling in catecholaminergic polymorphic ventricular tachycardia: a theoretical investigation. Am. J. Physiol. Heart Circ. Physiol., 301, H1625-H1638 (2011).

28) Yamada M, Ohta K, Niwa A, Tsujino N, Nakada T, Hirose M. Contribution of L-type $\mathrm{Ca}^{2+}$ channels to early afterdepolarizations induced by IKr and IKs channel suppression in guinea pig ventricular myocytes. J. Membr. Biol., 222, 151-166 (2008).

29) Haines DE, DiMarco JP. Current therapy for supraventricular tachycardia. Curr. Probl. Cardiol., 17, 411-477 (1992).

30) Dorian P. Rate control in atrial fibrillation. N. Engl. J. Med., 362, 1439-1441 (2010).

31) Singh BN, Nademanee K. Use of calcium antagonists for cardiac arrhythmias. Am. J. Cardiol., 59, 153B-162B (1987). 